\title{
Fracionamento dos carboidratos e proteínas de silagens de milho, sorgo e girassol
}

\author{
Fractionation of carbohydrate and protein of corn, sorghum and sunflower silages
}

\author{
Renius Mello $^{1}$ José Laerte Nörnberg $^{2}$
}

\section{RESUMO}

\begin{abstract}
O trabalho caracteriza e quantifica as frações dos carboidratos e proteínas de silagens de milho, sorgo e girassol, com a finalidade de disponibilizar dados bromatológicos que possibilitem maximizar o aproveitamento desses alimentos e otimizar o desempenho animal. Foram avaliados dois híbridos de milho (Zea mays), DKB-215 e DKB-344, dois híbridos de sorgo (Sorghum bicolor), Ambar e AG-2005 e dois híbridos de girassol (Helianthus annuus), Rumbosol e M-734. A silagem de girassol apresentou menor valor de carboidratos totais $(C T)$ e $B_{2}$ (celulose e hemicelulose) e maior de C (lignina e fibra associada à lignina). A silagem de milho apresentou maior valor de carboidratos não-fibrosos $(C N F), A+B_{l}$ (açúcares solúveis + amido e pectina) e de CT juntamente com a silagem de sorgo, enquanto a de sorgo apresentou maior valor de $B_{2}$ em função da maior contribuição de colmo. Houve diferença entre híbridos dentro da cultura do girassol para CT, sendo que o Rumbosol obteve maior valor que o M-734, em razão da aptidão dos mesmos, forrageiro e granifero respectivamente. A silagem de girassol apresentou maior valor de proteína bruta $(P B)$ e de suas frações. Não foi observada diferença entre híbridos nos valores de PB e de suas frações.
\end{abstract}

Palavras-chave: avaliação de alimentos, CNCPS, conservação de forragens, plantas forrageiras.

\section{ABSTRACT}

This work evaluates and characterizes the carbohydrates and proteins fractions of corn, sorghum and sunflower silages. The purpose was to supply composition data that make it possible to maximize use of foods and optimize animal performance. Two corn (Zea mays) hybrids, DKB-215 and DKB344; sorghum (Sorghum bicolor) hybrids, Ambar and AG-2005; and sunflower (Helianthus annuus) hybrids, Rumbosol and M734; were evaluated. Sunflower silage showed the lowest total carbohydrates (TC) and $B_{2}$ (cellulose and hemicelluloses) values and the highest content of $C$ (lignin and fiber associated lignin). Corn silages showed higher non-fiber carbohydrates (NFC), $A+B_{l}$ (soluble sugars + starch and pectin) and TC together sorghum silage while the last one showed higher $B_{2}$ due to higher stem contribution. There were differences between hybrids of sunflower for TC, when Rumbosol showed higher contents than M-734, due to the aptitude of these materials, forage and grain respectively. The sunflower silage showed higher crude protein $(C P)$ and protein fractions. There were no differences between hybrids for $\mathrm{CP}$ and protein fractions values.

Key words: chemical composition, CNCPS, conserved forages, feed evaluation, forages.

\section{INTRODUÇÃO}

Nos sistemas de produção de carne e leite em confinamento assim como na suplementação de pastagens durante períodos de escassez, a silagem é o principal volumoso utilizado (VIANA et al., 2002). Dos materiais empregados para ensilagem, a planta de milho (Zea mays) é considerada padrão, com valor nutritivo tomado como referência. Entretanto, sua produção e qualidade são incertas de ano para ano por ser muito influenciada pela disponibilidade de água no solo (NUSSIO, 1991). A cultura do sorgo (Sorghum bicolor), para a produção de silagem, vem sendo ampliada nos últimos anos, apresentando produção de matéria seca mais elevada que o milho, especialmente em condições marginais de cultivo como aquelas de regiões de solos com menor fertilidade e locais onde há estiagens longas e freqüentes (MOLINA, 2000). Todavia, verifica-se que a silagem de milho, geralmente, possui melhor qualidade nutricional que a de sorgo, com diferenças entre híbridos. Recentemente, o girassol (Helianthus annuus), a exemplo do sorgo, apresentase como planta forrageira alternativa em locais de baixas precipitações, mas, praticamente, sem avaliação do seu valor nutricional em comparação com as culturas de milho e sorgo.

'Zootecnista, Mestrando em Nutrição de Ruminantes, Universidade Federal de Viçosa (UFV). E-mail: reniusmello@ hotmail.com

${ }^{2}$ Médico Veterinário, Doutor, Professor, Núcleo Integrado de Desenvolvimento em Análises Laboratoriais (NIDAL) Departamento de Tecnologia e Ciência dos Alimentos (DTCA), Centro de Ciências Rurais (CCR), Universidade Federal de Santa Maria (UFSM), 97105-900, Santa MariaRS. E-mail: jlnornberg@smail.ufsm.br 
O valor nutricional de uma silagem depende, fundamentalmente, da cultivar utilizada, do estádio de maturação no momento do corte e da natureza do processo fermentativo o que refletirá diretamente na composição química e, conseqüentemente, no desempenho animal (VILELA, 1985). Da mesma forma, a qualidade da forragem está estreitamente relacionada com o consumo voluntário, sua digestibilidade e eficiência com que os nutrientes digeridos são utilizados pelo animal (CRAMPTON, 1957).

O suprimento das necessidades nutricionais dos ruminantes depende, principalmente, do conteúdo de energia e proteína da dieta, que podem ser utilizadas pela microbiota ruminal ou escapar da fermentação no rúmen, sendo absorvidos nos demais compartimentos do trato digestivo. A fermentação ruminal e a digestão pós-ruminal dependem da concentração total de carboidratos e proteínas na dieta e de suas taxas de degradação.

$\mathrm{O}$ avanço do conhecimento na nutrição de ruminantes, especialmente na última década, abriu espaço para que novos sistemas e metodologias de avaliação de alimentos sejam utilizados a fim de maximizar o seu uso pelos animais. Atualmente, as principais Tabelas de Exigências Nutricionais para Bovinos (NRC, 1996 e 2001) têm como base o Sistema Cornell (CNCPS - Cornell Net Carbohydrate and Protein System) para caracterização dos seus ingredientes. Esse sistema permite interpretações mecanísticas da função fisiológica, simulando de forma prática e confiável, a digestão e metabolização dos alimentos, gerando informações que podem ser utilizadas para estimar o valor nutricional, o consumo e o desempenho animal (FOX et al., 1992; RUSSEL et al., 1992; SNIFFEN et al., 1992). De acordo com o CNCPS, os alimentos são subdivididos em decorrência de suas características químicas, físicas, de degradação ruminal e digestibilidade pós-rúmen, visando minimizar as perdas de nutrientes, maximizando a eficiência de crescimento microbiano através da sincronização da degradação de carboidratos e proteínas para que ocorra o máximo desempenho teórico dos microrganismos, a fim de reduzir as perdas no rúmen, e também estimar o escape de nutrientes.

Os carboidratos totais, em conformidade com suas taxas de degradação são classificados em fração A (açúcares solúveis), que é prontamente fermentada no rúmen; $\mathrm{B}_{1}$ (amido e pectina), que apresenta taxa intermediária de degradação; fração $\mathrm{B}_{2}$ (celulose e hemicelulose), correspondendo à fração lenta e potencialmente digerível da parede celular; e fração $C$, representada pela porção indigerível ao longo do trato gastrointestinal (SNIFFEN et al., 1992). As proteínas são divididas em $A, B_{1}, B_{2}, B_{3}$ e C. A fração A é constituída de nitrogênio não protéico (NNP), que é de alta digestibilidade no rúmen, B representa a proteína verdadeira que é subdividida em três sub-frações, baseadas na velocidade de degradação ruminal, quando a $\mathrm{B}_{1}$ é rapidamente solúvel no rúmen (albumina e globulina), $\mathrm{B}_{2}$ com taxa de degradação intermediária (maioria das albuminas e glutelinas), $\mathrm{B}_{3}$ é a proteína associada à parede celular e de degradação lenta (prolaminas, extensinas e proteínas desnaturadas) e por fim, a fração C que é composta de proteínas insolúveis em detergente ácido, ou seja, que não é digerível no rúmen e intestino (SNIFFEN et al., 1992).

Diante desse contexto, o presente trabalho objetivou caracterizar e quantificar, de forma comparativa, as frações de carboidratos e proteínas de silagens de híbridos de milho, sorgo e girassol.

\section{MATERIAL E MÉTODOS}

O experimento foi realizado no Núcleo Integrado de Desenvolvimento em Análises Laboratoriais (NIDAL) do Departamento de Tecnologia e Ciência dos Alimentos (DTCA) do Centro de Ciências Rurais (CCR) da Universidade Federal de Santa Maria (UFSM). O local está fisiograficamente situado na Depressão Central do Estado do Rio Grande do Sul, à altitude de 95 m, $29^{\circ}$ $43^{\prime}$ de latitude sul e $53^{\circ} 42^{\prime}$ de longitude oeste (BRASIL, 1973).

Os tratamentos foram compostos pelas silagens produzidas a partir de dois híbridos de milho (DKB-215 e DKB-344), sorgo (Ambar e AG-2005) e girassol (Rumbosol e M-734). O material experimental, oriundo do ano agrícola 2000/2001, foi ensilado no ponto farináceo em protótipos de silos, os quais foram abertos com 35 dias de fermentação.

As amostras das silagens, imediatamente após sua coleta, foram pré-secas em estufa com ventilação forçada a $60^{\circ} \mathrm{C}$ por 72 horas e moídas (moinho tipo Wiley) em peneiras com crivos de um milímetro. Nesse material, foram efetuadas as seguintes determinações bromatológicas: matéria seca (MS), matéria orgânica (MO), proteína bruta (PB), fibra insolúvel em detergente neutro (FDN), fibra insolúvel em detergente ácido (FDA), lignina em detergente ácido (LDA), nitrogênio insolúvel em detergente neutro (NIDN), nitrogênio insolúvel em detergente ácido (NIDA), nitrogênio não protéico (NNP), nitrogênio solúvel (NS) e extrato etéreo (EE). 
As determinações dos percentuais de MS, MO, PB, EE foram efetuadas conforme a AOAC (1995); os componentes da parede celular (FDN, FDA e LDA) segundo VAN SOEST et al. (1991); o NIDN, NIDA e NNP usando a metodologia descrita por LICITRA et al. (1996) e NS de acordo com KRISHNAMOORTHY et al. (1982). Estimaram-se os carboidratos totais (CT) e não fibrosos (CNF), conforme WEISS (1999).

Os carboidratos e as proteínas foram divididos em quatro $\left(A, B_{1}, B_{2}\right.$ e $\left.C\right)$ e cinco frações $\left(\mathrm{A}, \mathrm{B}_{1}, \mathrm{~B}_{2}, \mathrm{~B}_{3}\right.$ e $\left.\mathrm{C}\right)$, respectivamente, sendo calculados através das equações descritas pelo NRC (1996) utilizando-se os resultados obtidos ao se determinar a composição química acima citada e expressos em $\mathrm{gkg}^{-1}$ de MS. Devido às dificuldades metodológicas para determinação de amido e pectina, as frações $A$ e $B_{1}$ foram expressas em conjunto e obtidas pela diferença entre $100-\left(B_{2}+C\right)$.

O delineamento experimental foi de blocos ao acaso num arranjo fatorial incompleto $3 \mathrm{x}$ 2 (3 culturas x 2 híbridos), e três repetições cada. A análise de variância para culturas foi efetuada pelo procedimento GLM (General Linear Models Procedure) e as médias comparadas pelo teste de Tukey em nível de significância de $5 \%$ de probabilidade de erro. A análise de variância dos híbridos dentro da cultura foi efetuada pelo procedimento Nested (aninhamento), em que a probabilidade do " $F$ " foi suficiente para indicar diferenças entre as médias dos híbridos (dois de cada cultura). As análises estatísticas foram efetuadas utilizando-se o programa estatístico SAS (1993).

\section{RESULTADOS E DISCUSSÃO}

Os resultados, expressos em base seca, referentes aos valores de carboidratos totais (CT), carboidratos não fibrosos (CNF) e das frações $A+B_{1}$, $\mathrm{B}_{2}$ e $\mathrm{C}$ das silagens de híbridos de milho, sorgo e girassol, encontra-se na tabela 1 . Verificou-se diferença significativa para CT. As silagens de girassol apresentaram valores menores de $\mathrm{CT}$ em relação às silagens de milho e sorgo em razão do maior teor de proteína bruta e extrato etéreo na primeira. Os teores de CT, observados para as silagens de milho e sorgo, situam-se entre os valores de $818 \mathrm{~g} \mathrm{~kg}^{-1}$ (CNCPS, 2002) e $891,1 \mathrm{~g} \mathrm{~kg}^{-1}$ (BACKES, 1998). Houve diferença significativa entre híbridos dentro da cultura. A silagem do híbrido Rumbosol apresentou maior valor de CT frente à silagem do M-734, em função do menor teor de extrato etéreo no Rumbosol $(14,1 \%)$ e maior no M-734 (20,34\%), justificado pela aptidão dos híbridos, pois o primeiro é forrageiro e o segundo granífero. Os valores de carboidratos totais obtidos neste estudo estão de acordo com aqueles relatados por VAN SOEST (1994), constituindo 50 a $80 \%$ da matéria seca das plantas forrageiras. Considerando que os carboidratos representam a principal fonte de energia para a fermentação microbiana, convertendo-os em ácidos graxos voláteis (AGV), as silagens de milho e sorgo foram superiores à silagem de girassol.

Analisando-se os CNF (Tabela 1), verificase que a silagem de milho apresentou os maiores valores $(\mathrm{P}<0,05)$ em comparação com sorgo e girassol. Isso se deve à maior contribuição de espiga na massa ensilada quando comparada à cultura do sorgo (Tabela 2) e

Tabela 1 - Carboidratos totais, carboidratos não fibrosos e frações dos carboidratos totais em $\mathrm{A}+\mathrm{B}_{1}, \mathrm{~B}_{2}$ e $\mathrm{C}$ de silagens dos híbridos de milho, sorgo e girassol

\begin{tabular}{|c|c|c|c|c|c|c|}
\hline Cultura & Híhridos & $\mathrm{CT}^{1}$ & $\mathrm{CNF}^{1}$ & $\mathrm{~A}+\mathrm{B}_{1}{ }^{1}$ & $\mathrm{~B}_{2}{ }^{1}$ & $\mathrm{C}^{1}$ \\
\hline \multirow{3}{*}{ Milho } & DKB-215 & 861,03 & 351,57 & 339,37 & $414,05 a$ & 107,60 \\
\hline & DKB-344 & 856,90 & 400,67 & 390,30 & $344,67 b$ & 121,93 \\
\hline & Média & $858,97 \mathrm{~A}^{2}$ & $376,12 \mathrm{~A}$ & $364,84 \mathrm{~A}$ & $379,36 \mathrm{~B}$ & $114,77 \mathrm{~B}$ \\
\hline \multirow{3}{*}{ Sorgo } & Ambar & 871,13 & 269,20 & 265,45 & 491,16 & 114,52 \\
\hline & AG-2005 & 872,63 & 268,77 & 259,39 & 485,07 & 128,17 \\
\hline & Média & $871,88 \mathrm{~A}$ & $268,98 \mathrm{~B}$ & $262,42 \mathrm{~B}$ & $488,11 \mathrm{~A}$ & $121,35 \mathrm{~B}$ \\
\hline \multirow{3}{*}{ Girassol } & Rumbosol & $667,37 a^{3}$ & 272,03 & 271,10 & 232,91 & 163,36 \\
\hline & M-734 & $608,47 b$ & 220,37 & 219,32 & 207,40 & 181,77 \\
\hline & Média & $637,92 \mathrm{~B}$ & $246,20 \mathrm{~B}$ & $245,21 \mathrm{~B}$ & $220,15 \mathrm{C}$ & $172,57 \mathrm{~A}$ \\
\hline Média geral & & 789,59 & 297,10 & 290,82 & 362,54 & 136,23 \\
\hline $\mathrm{CV}(\%)$ & & 2,38 & 13,45 & 15,07 & 10,55 & 16,78 \\
\hline
\end{tabular}

${ }^{1} \mathrm{CT}=$ carboidratos totais; $\mathrm{CNF}=$ carboidratos não fibrosos; $\mathrm{A}+\mathrm{B}_{1}=$ açúcares solúveis mais amido e pectina; $\mathrm{B}_{2}=$ celulose mais hemicelulose $\mathrm{C}=$ lignina mais fibra associada à lignina.

${ }^{2}$ Médias seguidas por letras maiúsculas distintas, dentro da coluna, diferem entre culturas $(\mathrm{P}<0,05)$ pelo teste de Tukey.

${ }^{3}$ Médias seguidas por letras minúsculas distintas, dentro da coluna, diferem entre híbridos dentro da cultura $(\mathrm{P}<0,05)$ pelo Nested. 
Tabela 2 - Proteína bruta e frações da proteína em A; $\mathrm{B}_{1} ; \mathrm{B}_{2} ; \mathrm{B}_{3}$ e $\mathrm{C}$ de silagens dos híbridos de milho, sorgo e girassol.

\begin{tabular}{|c|c|c|c|c|c|c|c|}
\hline & & $\mathrm{PB}^{1}$ & $\mathrm{~A}^{1}$ & $\mathrm{~B}_{1}{ }^{1}$ & $\mathrm{~B}_{2}{ }^{1}$ & $\mathrm{~B}_{3}{ }^{1}$ & $\mathrm{C}^{1}$ \\
\hline \multirow{3}{*}{ Milho } & DKB-215 & 61,50 & 32,84 & 0 & 15,20 & 11,09 & 2,38 \\
\hline & DKB-344 & 57,13 & 29,22 & 0 & 13,91 & 10,07 & 3,94 \\
\hline & Média & $59,32 b^{2}$ & $31,03 \mathrm{~b}$ & - & $14,56 \mathrm{~b}$ & $10,58 \mathrm{ab}$ & $3,16 \mathrm{~b}$ \\
\hline \multirow{3}{*}{ Sorgo } & Ambar & 47,77 & 23,45 & 0 & 12,35 & 8,28 & 3,68 \\
\hline & AG-2005 & 49,83 & 23,13 & 0 & 9,67 & 10,16 & 6,87 \\
\hline & Média & $48,80 \mathrm{c}$ & $23,29 b$ & - & $11,01 \mathrm{~b}$ & $9,22 b$ & $5,27 \mathrm{~b}$ \\
\hline \multirow{3}{*}{ Girassol } & Rumbosol & 114,13 & 60,38 & 0 & 21,55 & 21,84 & 10,37 \\
\hline & M-734 & 112,10 & 62,60 & 0 & 26,31 & 13,22 & 9,96 \\
\hline & Média & $113,12 \mathrm{a}$ & $61,49 a$ & - & $23,93 \mathrm{a}$ & $17,53 \mathrm{a}$ & $10,16 \mathrm{a}$ \\
\hline \multicolumn{2}{|c|}{ Média geral } & 73,74 & 38,60 & - & 16,50 & 12,44 & 6,20 \\
\hline \multicolumn{2}{|c|}{$\mathrm{CV}(\%)$} & 6,82 & 12,77 & - & 22,47 & 33,45 & 34,21 \\
\hline
\end{tabular}

${ }^{1} \mathrm{~PB}=$ proteína bruta; $\mathrm{A}=$ nitrogênio não protéico; $\mathrm{B}_{1}=$ globulinas e albuminas; $\mathrm{B}_{2}=$ maioria das albuminas e glutelinas; $\mathrm{B}_{3}=$ prolaminas, extensinas e proteína desnaturada; $\mathrm{C}=$ proteína insolúvel em detergente ácido.

${ }^{2}$ médias seguidas por letras distintas, dentro da coluna, diferem entre culturas $(\mathrm{P}<0,05)$ pelo teste de Tukey.

ao menor teor protéico e lipídico quando comparada à cultura do girassol. Valores próximos aos obtidos neste estudo foram observados por BACKES (1998), 271,1 e $280,9 \mathrm{~g} \mathrm{~kg}^{-1}$ para silagem de milho sem e com inoculante bacteriano; e $358,0 \mathrm{~g} \mathrm{~kg}^{-1}$ para silagem de milho descrito pelo CNCPS (2002). Não foi encontrada diferença $(\mathrm{P}>0,05)$ entre híbridos para CNF. Os CNF representam os carboidratos solúveis em detergente neutro, ou seja, o conteúdo celular, composto de açúcares (glicose, frutose), ácidos orgânicos e outros carboidratos de reserva das plantas, tais como: amido, sacarose e frutosanas (SNIFFEN et al., 1992; FOX et al., 1995; NRC, 1996; NRC, 2001; HALL, 2001). Assim, os CNF correspondem às frações $\mathrm{A}_{\text {e }} \mathrm{B}_{1}$, enquanto os carboidratos fibrosos (CF) formam as frações $B_{2}$ e $C$. De acordo com as definições do modelo, a fração A consiste de açúcares e a fração $B_{1}$ consiste de amido, pectina e glucanas (SNIFFEN et al., 1992).

Houve diferença $(\mathrm{P}<0,05)$ para as frações de carboidratos. Valores mais elevados de $\mathrm{A}+\mathrm{B}_{1}$ foram observados nas silagens de milho, de $\mathrm{B}_{2}$ nas silagens de sorgo e de $\mathrm{C}$ nas silagens de girassol (Tabela 1). As diferenças entre culturas são justificadas, em grande parte, pelas diferenças nas características estruturais das plantas (Tabela 2). A silagem de girassol obteve valores menores de $\mathrm{B}_{2}$ e maiores de $\mathrm{C}$, haja vista que essa cultura apresentou menor teor de FDN (promovido pela ausência ou pequena concentração de hemicelulose) e maior de lignina como percentagem da FDN. O valor mais elevado de $\mathrm{B}_{2}$ na silagem de sorgo deveu-se, principalmente, à maior participação de colmo. Valores semelhantes de
$\mathrm{A}+\mathrm{B}_{1} 339,9 \mathrm{~g} \mathrm{~kg}^{-1} ; \mathrm{B}_{2} 509,6 \mathrm{~g} \mathrm{~kg}^{-1}$ e C $153,4 \mathrm{~g} \mathrm{~kg}^{-1}$ para silagem de milho foram relatados por VALADARES FILHO et al. (2002). Também avaliando silagens, VIANA et al. (2002) encontraram teores de: 210 a 440; 346 e $316 \mathrm{~g} \mathrm{~kg}^{-1}$ de $\mathrm{A}+\mathrm{B}_{1} 250$ a 629; 414 e $296 \mathrm{~g}$ $\mathrm{kg}^{-1}$ de $\mathrm{B}_{2}$ e 130 a $310 ; 240$ e $388 \mathrm{~g} \mathrm{~kg}^{-1}$ de $\mathrm{C}$, para milho, sorgo e girassol, respectivamente. Estes dados demonstram a diversidade de resultados entre culturas e híbridos, mostrando a importância de fracionar os mesmos para o adequado balanceamento da dieta.

Os resultados referentes aos valores de proteína e suas frações encontram-se na Tabela 3. Não houve diferenças entre híbridos, entretanto, houve diferença $(\mathrm{P}<0,05)$ entre culturas. A silagem de girassol apresentou maior valor de $\mathrm{PB}\left(113,12 \mathrm{~g} \mathrm{~kg}^{-1}\right)$, seguida do milho $\left(59,32 \mathrm{~g} \mathrm{~kg}^{-1}\right)$, e esta, do sorgo $\left(48,80 \mathrm{~g} \mathrm{~kg}^{-1}\right)$. Com exceção da silagem de girassol, as demais culturas apresentaram valores de proteína bruta baixos, ou seja, inferiores a 7\%, nível mínimo para um adequado funcionamento da microbiota do rúmen (VAN SOEST, 1994). Este fato pode ser explicado, especialmente na silagem de sorgo em função da baixa contribuição de panículas (Tabela 2) na massa ensilada. Por outro lado, os teores de PB observados encontram-se dentro da faixa de 45 a $82 \mathrm{~g} \mathrm{~kg}^{-1}$ registradas por WHITE et al. (1988) para silagens de 80 híbridos de sorgo. Tendo em vista que as alterações na fração nitrogenada, ao final da ensilagem, podem apresentar conteúdo de proteína verdadeira de até $30 \%$ do nitrogênio total (McDONALD et al., 1991) a dosagem de PB em silagens é de pouco significado nutricional (CUNNIFF, 1995).

Analisando-se a fração A, composta por nitrogênio não protéico (NNP), às silagens de milho e

Ciência Rural, v.34, n.5, set-out, 2004. 
Tabela 3 - Contribuição dos componentes estruturais: colmo, folhas e espiga/panícula/capítulo de híbridos de milho, sorgo e girassol, respectivamente.

\begin{tabular}{|c|c|c|c|c|}
\hline \multirow{2}{*}{ Cultura } & \multirow{2}{*}{ Híbridos } & Colmo & Folhas & Espiga/Panícula/Capítulo \\
\hline & & \multicolumn{3}{|c|}{${ }$} \\
\hline \multirow{3}{*}{ Milho } & DKB - 215 & 25,08 & 09,25 & 65,67 \\
\hline & DKB - 344 & 29,33 & 09,53 & 61,14 \\
\hline & Média & $27,20 \mathrm{~B}^{1}$ & $09,39 \mathrm{~B}$ & $63,41 \mathrm{~A}$ \\
\hline \multirow{3}{*}{ Sorgo } & Âmbar & 68,90 & 10,99 & 20,11 \\
\hline & AG-2005 & 64,58 & 14,40 & 21,02 \\
\hline & Média & $66,74 \mathrm{~A}$ & $12,70 \mathrm{~B}$ & $20,56 \mathrm{~B}$ \\
\hline \multirow{3}{*}{ Girassol } & Rumbosol & 26,80 & $22,68 \mathrm{a}^{2}$ & 50,52 \\
\hline & M - 734 & 24,15 & $16,65 b$ & 59,20 \\
\hline & Média & $25,48 \mathrm{~B}$ & $19,66 \mathrm{~A}$ & $54,86 \mathrm{~A}$ \\
\hline Média geral & & 13,91 & 39,81 & 13,91 \\
\hline $\mathrm{CV}(\%)$ & & 19,69 & 18,03 & 19,69 \\
\hline
\end{tabular}

1.Médias seguidas por letras maiúsculas distintas, dentro da coluna, diferem entre culturas $(\mathrm{P}<0,05)$ pelo teste de Tukey.

2.Médias seguidas por letras minúsculas distintas, dentro da coluna, diferem entre híbridos dentro da cultura $(\mathrm{P}<0,05)$ pelo Nested.

sorgo apresentaram resultados inferiores $(\mathrm{P}<0,05)$ ao girassol. Valores percentuais, semelhantes às deste estudo, foram descritos por VAN SOEST (1994) 450 a $550 \mathrm{~g} \mathrm{~kg}^{-1}$ e NRC (2001) 424 a $513,9 \mathrm{~g} \mathrm{~kg}^{-1}$ para silagens de milho e sorgo, entretanto, concentrações inferiores foram obtidas por BACKES (1998), com valores de 210,7 e $275,0 \mathrm{~g} \mathrm{~kg}^{-1}$ para silagem de milho com e sem inoculante, respectivamente; e por MALAFAIA et al. (1996) 240,4g kg-1 e VALADARES FILHO et al. (2002) $317,6 \mathrm{~g} \mathrm{~kg}^{-1}$ para silagem de milho.

$A$ fração $B_{1}$ não foi encontrada pois, em função desta fração ser altamente degradável, provavelmente faça parte da fração A como conseqüência do processo fermentativo. VAN SOEST (1994) também não encontrou contribuições da fração $\mathrm{B}_{1}$ da proteína em silagens de milho e sorgo. Entretanto, valores de $104 ; 86,7$ e $49,1 \mathrm{~g} \mathrm{~kg}^{-1}$ de $\mathrm{B}_{1}$, foram encontrados por BACKES (1998), MALAFAIA et al. (1996) e VALADARES FILHO et al. (2002), respectivamente. Informações sobre o conteúdo de NNP e proteína verdadeira do nitrogênio solúvel são escassos. Pequena fração de proteína verdadeira $\left(B_{1}\right)$ foi obtida em diferentes forragens, porém alta variação foi observada em alimentos concentrados (KRISHNAMOORTHY et al., 1982). Outros autores, também encontraram deficiência da fração $B_{1}$ (altamente degradável no rúmen) na proteína de forrageiras (RUSSEL et al., 1992; SNIFFEN et al., 1992). No CNCPS toda a fração $B_{1}$ é considerada como sendo degradada no rúmen (SNIFFEN et al., 1992), portanto em conjunto com NNP são utilizados pela microbiota ruminal.

Frações $\mathrm{B}_{2}$ e $\mathrm{B}_{3}$, de forma semelhante à fração $\mathrm{A}$, foram maiores $(\mathrm{P}<0,05)$ para a silagem de girassol. Os valores médios percentuais da fração $\mathrm{B}_{2}$ e $\mathrm{B}_{3}$ estão entre os encontrados por VAN SOEST
(1994) 50 a $390 \mathrm{~g} \mathrm{~kg}^{-1}$ para $\mathrm{B}_{2}$ e 70 a $450 \mathrm{~g} \mathrm{~kg}^{-1}$ para $\mathrm{B}_{3}$ em silagens de milho e sorgo, em que pese à grande amplitude observada. Valores de 302 a $410 \mathrm{~g} \mathrm{~kg}^{-1}$ da fração $B\left(B_{1}+B_{2}+B_{3}\right)$ em silagens de milho são registrados no NRC (2001). Teores de $B_{2}$ mais elevados para silagem de milho foram obtidos por MALAFAIA et al. (1996) 402 $\mathrm{g} \mathrm{kg}^{-1}$, BACKES (1998) $412,8 \mathrm{~g} \mathrm{~kg}^{-1}$ e VALADARES FILHO et al. (2002) $417,9 \mathrm{~g} \mathrm{~kg}^{-1}$, entretanto, os mesmos autores relataram valores inferiores de $\mathrm{B}_{3}$ 147,7; 103,9 e 85,4 $\mathrm{g} \mathrm{kg}^{-1}$, respectivamente.

A fração $C$ seguiu a mesma relação observada nas demais frações protéicas, ou seja, valores mais elevados para silagens de girassol, em comparação com as silagens de milho e sorgo, que não diferiram $(\mathrm{P}>0,05)$ entre si. Os valores percentuais desta fração $\left(3,16 ; 5,27\right.$ e $10,16 \mathrm{~g} \mathrm{~kg}^{-1}$ para milho, sorgo e girassol, respectivamente) situaram-se abaixo dos mencionados por MALAFAIA et al. (1996) $122,5 \mathrm{~g} \mathrm{~kg}^{-1}$, NRC (2001) $185 \mathrm{~g} \mathrm{~kg}^{-1}$, e VALADARES FILHO et al. (2002) 119, $1 \mathrm{~g} \mathrm{~kg}^{-1}$, no entanto, semelhantes aos registrados por VAN SOEST (1994) $90 \mathrm{~g} \mathrm{~kg}^{-1}$ e BACKES (1998) 104,3 $\mathrm{g} \mathrm{kg}^{-1}$, quando comparados às silagens de sorgo e girassol.

\section{CONCLUSÕES}

As silagens de girassol apresentam valores menores de carboidratos totais, com frações menores de celulose mais hemicelulose e maiores de lignina mais fibra associada à lignina, enquanto as frações de carboidratos não fibrosos e de açúcares solúveis mais amido e pectina são semelhantes às silagens de sorgo, mas inferiores as silagens de milho. As silagens de girassol apresentam maiores valores protéicos que as silagens de sorgo e milho, refletindo-se em todas 
frações constituintes, mas com percentuais semelhantes. A contribuição dos componentes estruturais da planta exerce grande influência sobre o fracionamento dos carboidratos e proteínas.

\section{REFERÊNCIAS BIBLIOGRÁFICAS}

AOAC - ASSOCIATION OF OFFICIAL ANALYTICAL CHEMISTRY. 1995. Official methods of analysis. 16.ed. Washington, DC.: AOAC, 1995. 2000p.

BACKES, A.A. Desempenho, composição corporal, exigências nutricionais e validação de diferentes sistemas de arraçoamento para novilhos confinados. 1998. 160f. Dissertação (Mestrado em Zootecnia) - Curso de Pós-graduação em Zootecnia, Universidade Federal de Santa Maria.

BRASIL. Ministério da Agricultura. Levantamento de reconhecimento dos solos do estado do Rio Grande do Sul. Rio de Janeiro : Departamento Regional de Pesquisa Agropecuária: Divisão de Pesquisas Pedológicas, 1973. 431p. (DNPEA, Boletim Técnico, 30).

CNCPS. Cornell net carbohydrate and protein system. Ithaca: Cornell University, 2002. Software, version 5.0.18.

CRAMPTON, E.W. Interrelations between digestible nutrient and energy content, voluntary dry matter, intake and the overall. Journal of Animal Science, v.16, n.3, p.546-552, 1957.

CUNNIFF, P. Edition. Official methods of analysis of AOAC, 16.ed. Arlington, Washington, D.C. : AOAC, 1995. V.1, 2000p.

FOX, D.G. et al. Application of the Cornell net carbohydrate and protein model for cattle consuming forages. Journal of Animal Science, v.73, p.267-277, 1995.

FOX, D.G. et al. A net carbohydrate and protein system for evaluating cattle diets: III - Cattle requirements and diet adequacy. Journal of Animal Science, v.70, n.12, p.3578-3596, 1992.

HALL, M.B. Neutral detergent-soluble carbohydrates: nutritional relevance and analysis, a laboratory manual. Gainesville : University of Florida, 2000. (Extension Bulletin, 339).

KRISHNAMOORTHY, U. et al. Nitrogen fractions in selected feedstuffs. Journal of Dairy Science, v.65, p.217-225, 1982.

LICITRA, G.; HERNANDEZ, T.M.; VAN SOEST, P.J. Standardization of procedures for nitrogen fractionation of ruminant feeds. Animal Feed Science and Technology, v.57, p.347-358, 1996.

MALAFAIA, P.A.M. et al. Determinação das frações que constituem a proteína bruta de alguns volumosos e concentrados. In: REUNIÃO ANUAL DA SOCIEDADE BRASILEIRA DE ZOOTECNIA, 32., 1996, Fortaleza, CE. Anais... Fortaleza : SBZ, 1996, p.302-305.

McDOnALD, P.; HENDERSON, A.R.; HERON, S. The biochemistry of silage. Marlow : Chalcombe, 1991. 340p.

MOLINA, L.R. Avaliação nutricional de seis genótipos de sorgo colhidos em três estágios de maturação. 2000. 65f. Dissertação (Mestrado em Zootecnia) - Curso de Pós-graduação em Zootecnia da Escola de Veterinária da Universidade Federal de Minas Gerais.

NRC - NATIONAL RESEARCH COUNCIL. Nutrient requeriments of beef cattle. 7.ed. Washington D.C.: National Academy, 1996. 404p.

NRC - NATIONAL RESEARCH COUNCIL. Nutrient requeriments of dairy cattle. 7.ed. Washington D.C.: National Academy, 2001. 381p.

NUSSIO, L.G. Cultura de milho para a produção de silagem de alto valor alimentício. In: SIMPÓSIO SOBRE NUTRIÇÃO DE BOVINOS, 1991, Piracicaba, SP. Anais... Piracicaba : FEALQ, 1991. p.59-168.

RUSSEL, J.B. et al. A net carbohydrate and protein system for evaluation cattle diets: I - Ruminal fermentation. Journal of Animal Science, v.70, n.12, p.3551-3581, 1992.

SAS, INSTITUTE. SAS/STAT user's guide: statistics. 4.ed. Version 6. Cary, NC, 1993. V.2. 943p.

SNIFFEN, C.J. et al. A net carbohydrate and protein system for evaluating cattle diets: II - Carbohydrate and protein availability. Journal of Animal Science, v.70, n.12, p.3562-3577, 1992.

VALADARES FILHO, S.C.; ROCHA JÚNIOR, V.R.; CAPPELLE, E.R. Tabelas brasileiras de composição de alimentos para bovinos - cqbal 2.0. Viçosa : UFV, DZO, DPI, 2002. $297 \mathrm{p}$.

VAN SOEST, P.J. Nutritional ecology of the ruminant. 2.ed. Ithaca, New York : Cornell University, 1994. 476p.

VAN SOEST, P.J.; ROBERTSON, J.B.; LEWIS, B.A. Methods for dietary fiber, neutral detergent fiber, and nonstarch polysaccharides in relation to animal nutrition. Journal of Dairy Science, v.74, n.10, p.3583-3597, 1991.

VIANA, A.C. et al. Avaliação da degradabilidade in situ da fibra em detergente neutro e fracionamento dos carboidratos de silagens de milho (Zea mays), sorgo (Sorghum bicolor) e girassol (Helianthus annuus). In: CONGRESSO NACIONAL DE MILHO E SORGO, 24., 2002, Florianópolis, SC. Anais... Florianópolis: ABMS, 2002. CD-ROM.

VILELA, D. Sistemas de conservação de forragem. 1. silagem. Coronel Pacheco : EMBRAPA - CNPGL, 1985. 42p. (Boletim de Pesquisa, 11).

WEISS, W. Energy prediction equations for ruminant feeds. In: CORNELL NUTRITION CONFERENCE FOR FEED MANUFACTURERS, 61., 1999, Ithaca. Proceedings... Ithaca: Cornell University, 1999, p.176-185.

WHITE, J. et al. Seleting forage sorghum cultivars for silage. Manhattan : Kansas Agricultural Experimental Station, 1988. 8p. (KSU. Report of Progress, 539). 